\title{
ANALISIS KINERJA EKSPOR KOMODITAS KARET INDONESIA KE AMERIKA LATIN
}

\author{
Ghufrani Muharami ${ }^{1}$, dan Tanti Novianti ${ }^{2}$ \\ 1)Program Sarjana Departemen Ilmu Ekonomi, Fakultas Ekonomi dan Manajamen, Institut Pertanian Bogor \\ 2)Departemen Ilmu Ekonomi, Fakultas Ekonomi dan Manajemen, Institut Pertanian Bogor \\ e-mail : 1)muharami.eds@gmail.com
}

\begin{abstract}
Indonesias export dependency on traditional market can be minimized by diversifying export markets. Rubber (HS 4001-natural rubber) is one of Indonesias main export commodities to Latin America. Given Indonesias export growth to Latin America, the region could become potential market for diversifying export markets. This study aimed to analyze the competitiveness of rubber commodities and the factors affecting Indonesian rubber exports to Latin America. This study used secondary data ie cross section data of 6 export destination countries (Argentina, Brazil, Chile, Colombia, Mexico, and Peru) and time series data during 7 years (2009-2015). The analysis tools were RCA, EPD, and gravity model. Based on average RCA value, HS 4001 (natural rubber) Indonesias product is able to compete in Latin American market. Meanwhile EPD analysis identified, that Indonesias main commodities are on rising star, falling star, and retreat positions. Gravity model analysis showed that the factors which influence Indonesias export to America Latin were GDP of export destination countries, real exchange rate, export price, and economic distance.
\end{abstract}

Keywords: EPD, gravity model, IIT, Latin America, RCA.

\section{PENDAHULUAN}

Perdagangan internasional memegang peran penting dalam proses pembangunan ekonomi di berbagai negara. Perdagangan internasional mendorong keterbukaan negara-negara dalam melakukan kegiatan ekspor dan impor dengan menghilangkan berbagai hambatan yang ada. Dalam sistem perekonomian terbuka, negara cenderung mengandalkan kegiatan ekspor dibandingkan impor. Ekspor merupakan salah satu cara untuk meningkatkan penerimaan negara dan pada gilirannya dapat menstimulasi peningkatan Produk Domestik Bruto (PDB). Di sisi lain, ekspor dapat menarik aliran modal dari dalam dan luar negeri untuk digunakan dalam penciptaan lapangan kerja.

Keterbukaan ekonomi suatu negara terhadap perdagangan sering kali dicerminkan dengan rasio trade per GDP. Rasio ini merupakan perbandingan jumlah nilai ekspor dan impor terhadap total PDB. Tabel 1 menunjukkan rasio trade per GDP Indonesia yang berfluktuasi selama tahun 2006 sampai 2015. Perubahan presentase pada trade per GDP dapat disebabkan oleh banyak faktor.
Seperti yang terjadi pada tahun 2008, trade per GDP mencapai presentase sebesar 58,56 persen karena krisis yang terjadi di Amerika Serikat. Krisis menyebabkan nilai tukar melemah sehingga nilai komoditas yang diekspor dan diimpor menjadi lebih tinggi.

Tabel 1. Data dan Sumber Data yang Digunakan dalam Penelitian

\begin{tabular}{|c|c|}
\hline Tahun & $\begin{array}{c}\text { Tingkat keterbukaan } \\
\text { perdagangan (persen) }\end{array}$ \\
\hline 2006 & 56.6571 \\
2007 & 54.8293 \\
2008 & 58.5614 \\
2009 & 45.5121 \\
2010 & 46.7013 \\
2011 & 50.1800 \\
2012 & 49.5829 \\
2013 & 48.6374 \\
2014 & 48.0802 \\
2015 & 41.8736 \\
\hline
\end{tabular}

Sumber: Worldbank (2017)

Pada tahun 2011 sampai 2015, presentase trade per GDP cenderung mengalami penurunan. Hal ini disebabkan karena adanya 
penurunan nilai ekspor dan impor Indonesia ke pasar internasional. Tidak hanya nilai ekspor dan impor, peningkatan konsumsi masyarakat dan pengeluaran pemerintah dapat memengaruhi penurunan presentase trade per GDP. Meski demikian, presentase trade per GDP yang cukup besar memperlihatkan bahwa perdagangan berperan penting dalam pertumbuhan ekonomi Indonesia.

Perdagangan Indonesia secara garis besar terbagi atas sektor migas dan non migas. Data BPS (2017) menunjukkan nilai ekspor dan impor pada sektor migas dan non migas yang berfluktuasi. Nilai ekspor migas cenderung mengalami defisit dalam lima tahun terakhir akibat peningkatan impor dan turunnya ekspor minyak dan gas di tengah tren penurunan harga minyak dan komoditas dunia. Pada tahun 2014, neraca perdagangan sektor migas mengalami defisit tertinggi, yaitu sebesar US\$13,4 miliar. Sementara pada sektor non migas, meski nilai ekspor dan impor mengalami penurunan namun neraca perdagangan menunjukkan nilai positif sebesar US\$ 11,24 miliar dan ikut meningkat di tahun 2015 menjadi senilai US\$13,71 miliar.

Terjadinya defisit pada neraca perdagangan khususnya pada sektor migas serta penurunan nilai ekspor, tidak terlepas dari pengaruh perkonomian global. Perlambatan ekonomi global yang terjadi di negara mitra dagang Indonesia menandakan adanya per- lambatan ekonomi masyarakat di negara tujuan ekspor yang berimbas pada penurunan permintaan. Gambar 1 menunjukkan bahwa mitra dagang Indonesia dalam kurun waktu sepuluh tahun masih didominasi oleh negaranegara maju.

Pasar tradisional atau negara tujuan ekspor utama Indonesia yaitu Amerika Serikat, Jepang dan Uni Eropa yang menjadi andalan bagi komoditas ekspor Indonesia dapat menimbulkan dampak negatif. Ketergantungan terhadap suatu pasar tertentu sangat berisiko bagi perkembangan ekspor itu sendiri, terutama jika terjadi guncangan ekonomi di negara-negara tersebut. Untuk mempertahankan kinerja ekspor, diversifikasi pasar ekspor penting dilakukan. Diversifikasi pasar ekspor menjadi penting agar Indonesia tidak bergantung pada mitra dagang utama. Implementasi ini mulai diterapkan oleh Kementerian Perdagangan dengan mengubah fokus pasar tujuan ekspor. Pemerintah Indonesia tengah memfokuskan pada negara-negara berkembang atau pasar non-tradisional (emerging markets) sebagai negara tujuan ekspor Indonesia. Amerika Latin termasuk ke dalam pasar non-tradisional yang dipetakan oleh Kementerian Perdagangan dengan beberapa negara lain di kawasan Asia, Eropa Timur dan Eropa Tengah, Timur Tengah, Afrika, serta Australia Oceania.

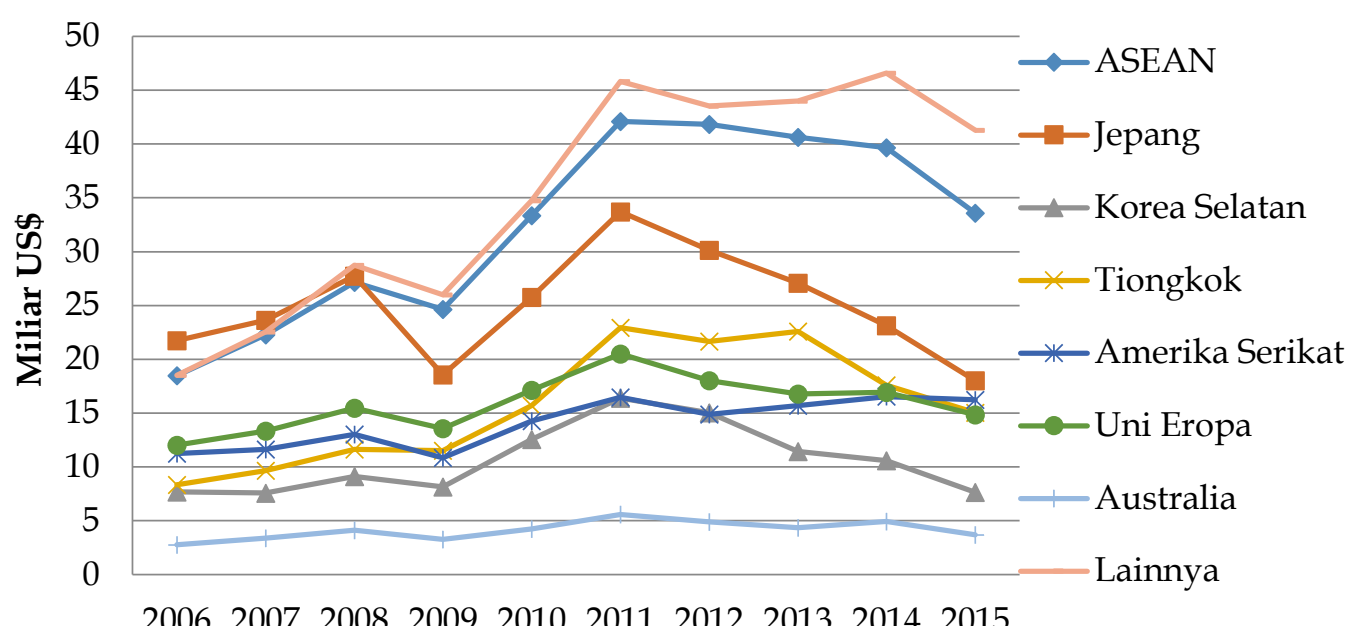

Gambar 1. Perkembangan Negara Tujuan Ekspor Utama Indonesia Tahun 2006-2015 Sumber: BPS, 2017 (diolah) 
Tabel 2. Total dan Share Ekspor Indonesia ke Dunia Tahun 2006-2015 (ribu US\$)

\begin{tabular}{|c|c|c|c|}
\hline Tahun & $\begin{array}{c}\text { Ekspor Indonesia } \\
\text { ke Amerika Latin }\end{array}$ & $\begin{array}{c}\text { Ekspor Indonesia } \\
\text { ke Dunia }\end{array}$ & $\begin{array}{c}\text { Share } \\
\text { (persen) }\end{array}$ \\
\hline 2006 & 1.632 .838 & 100.798 .616 & 1,62 \\
\hline 2007 & 1.873 .309 & 114.100 .873 & 1,64 \\
\hline 2008 & 2.274 .110 & 137.020 .424 & 1,66 \\
\hline 2009 & 1.987 .793 & 116.509 .992 & 1,71 \\
\hline 2010 & 3.363 .471 & 157.779 .103 & 2,13 \\
\hline 2011 & 3.821 .676 & 203.496 .619 & 1,88 \\
\hline 2012 & 3.477 .838 & 190.031 .839 & 1,83 \\
\hline 2013 & 3.508 .614 & 182.551 .754 & 1,92 \\
\hline 2014 & 3.556 .846 & 176.036 .194 & 2,02 \\
\hline
\end{tabular}

Sumber: Trademap, 2017 (diolah)

Diversifikasi pasar ekspor dapat dilakukan melalui peningkatan ekspor ke Amerika Latin. Tabel 2 menunjukkan share dan nilai ekspor Indonesia ke Amerika Latin dalam kurun waktu sepuluh tahun mengalami tren yang positif. Pada tahun 2010, nilai ekspor Indonesia ke Amerika Latin mengalami peningkatan cukup signifikan dibandingkan dengan nilai ekspor Indonesia ke dunia. Hal ini berdampak pada peningkatan share ekspor yang mencapai 2,13 persen. Pada tahun 2013 dan 2014, meski ekspor Indonesia ke dunia mengalami penurunan namun ekspor Indonesia ke Amerika Latin mengalami peningkatan sebesar US\$ 3.508.614 ribu dan US\$ 3.556.846 ribu.

Ekspor Indonesia ke pasar internasional terdiri dari berbagai macam komoditas. Komoditas-komoditas tersebut terbagi lagi ke dalam produk yang lebih spesifik. Harmonized System (HS) merupakan salah satu bentuk penomoran yang digunakan untuk pengklasifikasi produk perdagangan dan turunannya yang di kelola oleh World Custom Organization (WCO). Karet merupakan komoditas yang potensial untuk dikembangkan ke pasar Amerika Latin. Produk HS 4001 (natural rubber) adalah produk dengan nilai ekspor tertinggi dari Indonesia ke Amerika Latin selama tahun 2006 sampai 2015. Nilai ekspor yang tinggi diiringi dengan tren nilai ekspor yang positif sebesar 12,37 persen (Tabel 3).

Adanya peningkatan terhadap permintaan ekspor mendorong dayasaing produk Indonesia untuk ditingkatkan agar produk mampu bersaing di pasar tujuan ekspor. Dayasaing suatu produk akan menunjukkan sejauh mana produk tersebut memiliki keunggulan komparatif bagi negara pengekspor dibandingkan dengan negara pengekspor lainnya. Oleh karena itu penelitian ini bertujuan untuk menganalisis dayasaing produk serta faktor-faktor yang memengaruhi nilai ekspor produk.

Tabel 3. Nilai Ekspor dan Tren Produk HS 4001 (Natural Rubber) Tahun 2006-2015

\begin{tabular}{|c|c|c|}
\hline Tahun & $\begin{array}{c}\text { Nilai ekspor } \\
\text { HS 4001 } \\
\text { (ribu US\$) }\end{array}$ & $\begin{array}{c}\text { Tren } \\
\text { (persen) }\end{array}$ \\
\hline 2006 & 290.607 & \\
\hline 2007 & 297.581 & \\
2008 & 393.432 & \\
2009 & 190.692 & \\
2010 & 549.772 & \\
2011 & 753.595 & 12,3679 \\
\hline 2012 & 433.716 & \\
\hline 2013 & 407.065 & \\
\hline 2014 & 298.741 & \\
\hline 2015 & 233.189 & \\
\hline
\end{tabular}

Sumber: Trademap (2017) diolah

\section{METODE PENELITIAN}

Data yang digunakan dalam penelitian ini adalah data cross section 6 negara tujuan ekspor dan data time series selama 7 tahun, yaitu tahun 2009 sampai 2015. Negara yang menjadi objek penelitian ini adalah negara di kawasan Amerika Latin yang memiliki nilai impor terbesar dari Indonesia, yaitu Argentina, Brasil, Chili, Kolombia, Meksiko, 
dan Peru. Nilai ekspor dan impor merupakan nilai ekspor dan impor HS 4001 (natural rubber).

Metode analisis yang digunakan dalam penelitian ini adalah metode kuantitatif, yaitu estimasi dayasaing komoditas unggulan dianalisis menggunakan Revealed Comparative Advantage (RCA) dan Export Product Dynamics (EPD). Gravity model digunakan untuk mengestimasi faktor-faktor yang memengaruhi aliran ekspor produk unggulan Indonesia ke Amerika Latin. Pengolahan data dilakukan dengan software E-views 8.0 dan Microsoft Excel.

Metode RCA merupakan salah satu metode yang digunakan untuk mengukur keunggulan komparatif komoditas disuatu wilayah. Perhitungan RCA ini dapat mengidentifikasi apakah suatu komoditas ekspor di sebuah wilayah memiliki keuntungan komparatif atau tidak. Dengan RCA pula dapat dilihat pola spesialisasi ekspor suatu wilayah. Namun analisis ini memiliki kelemahan, yaitu sifatnya yang statis serta asumsi bahwa setiap negara mengekspor semua komoditas atau kelompok komoditas.

Pada dasarnya, metode RCA digunakan untuk menghitung pangsa nilai ekspor suatu komoditas terhadap total ekspor suatu komoditas suatu negara dibandingkan dengan pangsa nilai komoditas tersebut dalam perdagangan dunia. Bala Bassala, tokoh yang pertama kali memperkenalkan analisis RCA menghitung dayasaing suatu komoditas dengan perhitungan seperti pada persamaan (1).

$$
R C A=\frac{X k i / X i}{W k i / W i}
$$

Dimana:

Xki : nilai ekspor komoditas $\mathrm{k}$ dari negara i ke negara tujuan (US\$)

$\mathrm{Xi}_{\mathrm{i}}$ : nilai ekspor total dari negara i ke negara tujuan (US\$)

Wki : nilai ekspor komoditas $\mathrm{k}$ dari dunia ke negara tujuan (US\$)

Wt : nilai ekspor total dunia ke negara tujuan (US\$)
Jika nilai indeks RCA suatu negara untuk komoditas tertentu lebih besar dari satu, maka negara tersebut memiliki keunggulan komparatif di atas rata-rata dunia. Semakin besar nilai indeks RCA suatu komoditas, semakin tinggi pula tingkat keunggulan komparatifnya. Namun jika nilai indeks RCA kurang dari satu, maka keunggulan komparatif suatu negara untuk komoditas tersebut tergolong rendah.

Metode Export Product Dynamic (EPD) adalah metode yang digunakan untuk menganalisis dan mengidentifikasi produk atau komoditas yang mempunyai daya kompetitif tertinggi serta pertumbuhan produk atau barang yang cepat pada arus perdagangan ekspor dalam suatu negara (Pradipta, 2014). Pada analisis EPD terdapat matriks posisi dayasaing yang memperlihatkan share ekspor suatu negara dalam perdagangan dunia (share of country's export in world trade) dan share produk ekspor dalam perdagangan dunia (share of product in world trade) seperti pada Tabel 4.

Tabel 4. Matriks Posisi Dayasaing

\begin{tabular}{|c|c|c|}
\hline \multirow{2}{*}{$\begin{array}{l}\text { Share of } \\
\text { Country's } \\
\text { Export in } \\
\text { World Trade }\end{array}$} & \multicolumn{2}{|c|}{$\begin{array}{c}\text { Share of Product in World } \\
\text { Trade }\end{array}$} \\
\hline & $\begin{array}{c}\text { Rising } \\
\text { (Dynamic) }\end{array}$ & $\begin{array}{c}\text { Falling } \\
\text { (Stagnant) }\end{array}$ \\
\hline $\begin{array}{c}\text { Rising } \\
\text { (Competitive) }\end{array}$ & Rising Star & Falling Star \\
\hline $\begin{array}{l}\text { Falling (Non- } \\
\text { Competitive) }\end{array}$ & $\begin{array}{c}\text { Lost } \\
\text { Opportunity }\end{array}$ & Retreat \\
\hline
\end{tabular}

Sumber: Estherhuizen (2006)

Posisi pasar yang ideal adalah yang mempunyai pangsa pasar tertinggi pada ekspornya sebagai rising star, yang menunjukkan bahwa negara tersebut memperoleh tambahan pangsa pasar pada produk mereka yang bertumbuh cepat (fast-growing products). Lost opportunity, terkait dengan penurunan pangsa pasar pada produk-produk yang dinamis adalah yang posisi yang paling tidak diinginkan. Falling Star juga tidak disukai, meskipun masih lebih baik jika dibandingkan dengan Lost opportunity, karena pangsa pasarnya tetap meningkat. Sementara itu, retreat biasanya tidak diinginkan, tetapi pada kasus 
tertentu dapat diinginkan jika pergerakannya menjauhi produk-produk yang stagnan dan menuju produk-produk yang dinamik (Bappenas, 2009).

Dalam penelitian ini, secara sistematis pangsa pasar ekspor Indonesia dirumuskan pada persamaan (2) dan pangsa pasar produk ekspor Indonesia dalam perdagangan dunia dipersempit menjadi perdagangan di kawasan Amerika Latin seperti pada persamaan (3).

Sumbu X: Peningkatan pangsa pasar ekspor Indonesia

sumbu $X=\frac{\sum_{t=1}^{T}\left(\left(\frac{X i}{X t}\right)_{t} \times 100 \%-\left(\left(\frac{X i}{X t}\right)_{t-1} \times 100 \%\right)\right)}{T-1} \ldots .$.

Sumbu Y : Peningkatan pangsa pasar produk ekspor unggulan Indonesia di Amerika Latin

sumbu $Y=\frac{\sum_{t=1}^{T}\left(\left(\frac{W i}{W t}\right)_{t} \times 100 \%-\left(\left(\frac{W i}{W t}\right)_{t-1} \times 100 \%\right)\right)}{T-1} \ldots .$.

Dimana:

$\mathrm{Xi}$ : nilai ekspor produk Indonesia ke Amerika Latin (US\$)

Xt : nilai ekspor produk dunia ke Amerika Latin (US\$)

Wi : nilai ekspor total Indonesia ke Amerika Latin (US\$)

Wt : nilai ekspor total dunia ke Amerika Latin (US\$)

t : tahun ke-t

$\mathrm{T}$ : jumlah tahun analisis

Gravity model pertama kali dikenalkan oleh Tinbergen pada tahun 1962. Model ini sebenarnya dianggap sebagai salah satu cara yang paling bermanfaat untuk merumuskan dan menjelaskan arus perdagangan bilateral. Hatab et al. (2010) menjelaskan bahwa menurut Hukum Gravitasi yang ditemukan oleh Newton pada tahun 1687, model gravitasi hanya menjelaskan bahwa perdagangan antara dua negara ditentukan secara positif oleh PDB masing-masing negara, dan secara negatif berdasarkan jarak di antara keduanya (Hatab et al., 2010). Secara matematis model ini dapat dirumuskan pada persamaan (4).
$X_{i j}=\beta 0 Y_{i}^{\beta 1} Y_{j}^{\beta 2} D_{i j} \beta 3$

Dimana:

$X_{i j}$ : ekspor produk negara i ke negara $\mathrm{j}$

Yi : PDB eksportir

$Y j$ : PDB importir

Dij : jarak antara dua negara

Model yang digunakan dalam penelitian ini dilakukan dengan mentransformasikan variabel ke dalam bentuk ln (logaritma natural) dengan tujuan memenuhi uji asumsi klasik, kecuali variabel trade per GDP. Estimasi model yang digunakan mengacu pada penelitian Hatab et al. (2010) yang telah disesuaikan dengan beberapa variabel lainnya sebagai berikut:

$$
\begin{aligned}
L N_{-} X_{i t}= & \beta_{0}+\beta_{1} L N_{-} G D P_{j t}+\beta_{2} L N_{-} E C O D I S T_{t}+ \\
& \beta_{3} L N_{-} E P_{t}+\beta_{4} L N_{-} R E R_{t}+ \\
& \beta_{5} T R A D E_{-} G D P_{j t}+U_{i t} \ldots \ldots \ldots \ldots \ldots . . . \ldots
\end{aligned}
$$

Dimana:

LN_X $X_{i t}=$ nilai ekspor produk unggulan Indonesia pada tahun ke- $t$ (US\$)

$\mathrm{LN}_{-} \mathrm{GDP}_{j t}=$ PDB riil negara tujuan ekspor pada tahun ke- $t$ (US\$)

$\mathrm{LN}_{-} \mathrm{ECODIST}_{t}=$ jarak ekonomi antara Indonesia dengan negara tujuan ekspor $(\mathrm{km})$

LN_EP $P_{t} \quad=$ harga ekspor produk unggulan Indonesia (US\$/ton)

$\mathrm{LN} \_R E R_{t}=$ nilai tukar riil Indonesia terhadap negara tujuan ekspor pada tahun ke- $t$ (Rupiah terhadap LCU)

TRADE_GDP $_{j t}=$ tingkat keterbukaan perdagangan negara tujuan ekspor (persen)

$U_{i t}=$ errorterm

$a=$ intersep

$\beta_{n}=$ parameter yang diduga $(\mathrm{n}=1,2, \ldots)$

\section{HASIL DAN PEMBAHASAN}

ANALISIS DAYASAING PRODUK HS 4001 (NATURAL RUBBER)

Kinerja perdagangan Indonesia ke negara-negara di kawasan Amerika Latin dapat dilihat melalui keunggulan komparatifnya. Keunggulan komparatif menunjukkan bagaimana tingkat dayasaing komoditas yang 
Tabel 5. Nilai RCA Produk HS 4001 (Natural Rubber) Tahun 2009-2015

\begin{tabular}{|c|c|c|c|c|c|c|c|c|}
\hline \multirow{2}{*}{ Negara } & \multicolumn{8}{|c|}{ Tahun } \\
\hline & 2009 & 2010 & 2011 & 2012 & 2013 & 2014 & 2015 & Rata-rata \\
\hline Argentina & 140,22 & 121,36 & 136,77 & 143,38 & 145,82 & 177,95 & 167,69 & 147,60 \\
\hline Brasil & 54,13 & 53,25 & 58,61 & 55,62 & 53,51 & 62,90 & 63,02 & 57,29 \\
\hline Chili & 25,33 & 85,08 & 45,01 & 52,09 & 34,85 & 6,10 & 28,84 & 39,61 \\
\hline Kolombia & 109,90 & 103,81 & 104,17 & 85,82 & 186,68 & 65,22 & 54,42 & 101,43 \\
\hline Meksiko & 64,53 & 75,64 & 110,37 & 114,89 & 109,56 & 101,43 & 126,63 & 100,44 \\
\hline Peru & 1,69 & 39,97 & 24,83 & 11,76 & 78,76 & 42,46 & 54,51 & 36,28 \\
\hline
\end{tabular}

dieskpor oleh suatu negara. Salah satu metode yang dapat digunakan untuk mengukur keunggulan komparatif tersebut adalah metode RCA. Nilai RCA menunjukkan perbandingan antara pangsa ekspor komoditas suatu negara terhadap pangsa ekspor komoditas tersebut dari seluruh dunia. Dengan kata lain RCA menunjukkan keunggulan komparatif atau dayasaing ekspor dari suatu negara dalam suatu komoditas terhadap dunia. Jika hasil RCA dari komoditas tertentu bernilai lebih besar dari 1, maka komoditas tersebut memiliki keunggulan komparatif di atas rata-rata dunia. Sebaliknya, bila nilai RCA lebih kecil dari 1 berarti keunggulan komparatif untuk komoditas tersebut rendah atau di bawah rata-rata dunia.

Pada Tabel 5, hasil estimasi RCA untuk produk HS 4001 (natural rubber) bernilai lebih dari satu selama tahun 2009 sampai 2015 di keenam negara pengimpor. Sebagai produk penyumbang ekspor terbesar dari Indonesia ke Amerika Latin, produk HS4001 (natural rubber) memiliki dayasaing yang kuat dan mampu bersaing di pasar dunia. Argentina merupakan negara dengan rata-rata nilai RCA terbesar yaitu 147,60.

Tingkat dayasaing komoditas atau produk ekspor tidak hanya dapat diukur dengan metode RCA namun juga menggunakan metode EPD. Metode EPD ini dapat menangkap gambaran umum tentang dinamika ekspor suatu komoditas atau produk. Hasil analisis EPD memperlihatkan tingkat kedinamisan pertumbuhan ekspor pada suatu periode tertentu yang dikategorikan pada empat posisi pasar yaitu rising star, falling star, lost opportunity dan retreat. Posisi rising star merupakan posisi pasar yang paling ideal. Sementara retreat merupakan posisi yang paling tidak dinginkan karena produknya pun tidak diingikan lagi dalam pasar.

Pada Tabel 6 hasil estimasi EPD untuk produk HS 4001 (natural rubber) menempati tiga posisi. Kolombia menempati posisi retreat, Argentina dan Chili berada di posisi falling star, serta posisi rising star ditempati tiga negara lainnya. Posisi retreat merupakan posisi yang paling tidak diinginkan. Posisi ini mengindikasikan adanya penurunan pangsa pasar ekspor produk HS 4001 (natural rubber)

Tabel 6. Hasil EPD Produk HS 4001 (Natural Rubber) Indonesia ke Amerika Latin

\begin{tabular}{|l|r|r|l|}
\multirow{2}{*}{ Negara } & \multicolumn{3}{|c|}{ HS 4001 (natural rubber) } \\
\cline { 2 - 4 } & $\begin{array}{c}\text { Pertumbuhan Pangsa } \\
\text { Pasar Ekspor (\%) }\end{array}$ & $\begin{array}{c}\text { Pertumbuhan Pangsa } \\
\text { Pasar Produk (\%) }\end{array}$ & Posisi Dayasaing \\
\hline Argentina & 2,2395 & $-0,2035$ & Falling Star \\
\hline Brasil & 3,5048 & 0,5672 & Rising Star \\
\hline Chili & 56,5206 & $-8,4425$ & Falling Star \\
Kolombia & $-4,0441$ & $-0,2762$ & Retreat \\
\hline Meksiko & 17,8932 & 5,5260 & Rising Star \\
\hline Peru & 574,4246 & 12,5661 & Rising Star \\
\hline \multicolumn{1}{|c|}{ Rata-rata } & 108,4231 & 1,6228 & Rising Star \\
\hline
\end{tabular}


Indonesia di Kolombia sebesar 4,044 persen dan diikuti dengan penurunan pangsa pasar produk terhadap HS 4001 (natural rubber) Indonesia sebesar 0,276 persen. Hasil ini berdampak pada pertumbuhan pasar dan produk tersebut yang tidak lagi dinamis.

Posisi falling star merupakan posisi yang lebih baik daripada retreat. Meskipun pangsa pasar produk HS 4001 (natural rubber) di Argentina dan Chili mengalami penurunan, namun pangsa pasar ekspor mengalami peningkatan. Sementara posisi rising star adalah posisi yang sangat diinginkan karena baik pangsa pasar produk dan pangsa pasar ekspor mengalami peningkatan yang dinamis. Peru merupakan negara dengan nilai pangsa pasar ekspor dan pangsa pasar produk tertinggi dibadingkan kelima negara lainnya, yaitu sebesar 574,424 persen dan 12,566 persen. Secara rata-rata nilai, ekspor produk HS 4001 (natural rubber) Indonesia ke pasar Amerika Latin berada pada posisi rising star. Dengan demikian, Amerika latin dapat dijadikan pasar potensial untuk produk natural rubber (HS 4001) Indonesia dalam rangka diversifikasi pasar ekspornya.

\section{ANALISIS FAKTOR-FAKTOR YANG MEMENGARUHI EKSPOR KOMODITAS UNGGULAN INDONESIA KE AMERIKA LATIN}

Penelitian ini menggunakan Gravity model untuk menjelaskan faktor-faktor penentu ekspor produk HS 4001 (natural rubber) Indonesia ke Amerika Latin. Variabel dependen yang digunakan adalah nilai ekspor produk (Xit). Variabel independen yang digunakan adalah PDB riil enam negara tujuan ekspor Indonesia ke Amerika Latin (GDPjt), jarak ekonomi (ECODISTt), harga ekspor produk (EPt), nilai tukar riil (RERt), dan keterbukaan perdagangan (TRADE_ GDPjt). Seluruh variabel diubah ke dalam bentuk logaritma natural untuk menyamakan satuan, kecuali variabel TRADE_GDPjt.

Pemilihan kesesuaian model dilakukan dengan uji Chow dan Uji Hausman. Uji Chow digunakan untuk memilih model terbaik antara pooled least square (PLS) dengan fixed effect model (FEM). Hasil uji Chow pada Lampiran 1 menunjukkan nilai probabilitas sebesar 0.0000 (lebih kecil dari taraf nyata 5 persen). Artinya, hasil uji ini menolak model PLS sehingga model yang dipilih adalah FEM.

Uji Hausman digunakan untuk memilih model terbaik antara random effect model (REM) dan fixed effect model (FEM). Pada hasil uji Hausman menunjukkan nilai probabilitas lebih kecil dari taraf nyata 5 persen (Lampiran 2). Hasil tersebut menolak hipotesis random effect model sehingga fixed effect model dipilih sebagai model terbaik.

Model nilai ekspor produk HS 4001 (natural rubber):

$$
\begin{aligned}
\text { LN_Xit }= & -76,69+3,29 L N \_G D P J t- \\
& \text { 1,23LN_ECODIST + 1,37LN_EP }- \\
& \text { 0,60LN_RER + 0,01TRADE_GDP ...(6) }
\end{aligned}
$$

Tabel 7 memperlihatkan hasil estimasi faktor-faktor yang memengaruhi nilai ekspor HS 4001 (natural rubber) Indonesia ke Amerika Latin. Berdasarkan hasil analisis, PDB negara tujuan mempunyai hubungan positif dan signifikan terhadap nilai ekspor produk HS 4001 (natural rubber). Apabila terjadi peningkatan PDB negara tujuan ekspor sebesar 1 persen akan meningkatkan nilai ekspor sebesar 3,291 persen (ceteris paribus). Hasil estimasi ini telah sesuai dengan hipotesis penelitian. Menurut Ragazzhi (2012), PDB merupakan ukuran kapasitas penyerapan (absorsi). Semakin besar PDB negara tujuan ekspor, maka permintaan impor dari negara tujuan ekspor semakin besar. Dengan demikian ekspor dari negara asal semakin meningkat sehingga koefisien variabel PDB riil negara tujuan memiliki tanda positif (Ragazzhi, 2012). Adanya peningkatan PDB riil dapat mendorong masyarakat untuk mengkonsumsi barang lebih banyak sehingga permintaan akan barang tersebut dapat meningkat.

Variabel jarak ekonomi merupakan proksi dari biaya transportasi. Hasil analisis menunjukkan bahwa jarak ekonomi berpengaruh negatif dan signifikan pada taraf nyata 5 persen. Kenaikan jarak ekonomi 
Tabel 7. Hasil Estimasi Faktor-Faktor yang Memengaruhi Ekspor HS 4001 (Natural Rubber) Unggulan Indonesia ke Amerika Latin

$\begin{array}{lrr} & \text { Koefisien } & \text { Prob. } \\ \text { LN_RER } & -0,601937 & 0,0587^{* *} \\ \text { LN_GDPJ } & 3,291318 & 0,0003^{*} \\ \text { LN_EP } & 1,371492 & 0,0000^{*} \\ \text { LN_ECODIST } & -1,233308 & 0,0000^{*} \\ \text { TRADE_GDP } & 0,008199 & 0,2894 \\ \text { C } & -76,68555 & 0,0003^{*} \\ & \text { Weighted Statistics } & 0,993427 \\ \text { R-squared } & & 0,000000 \\ \text { Prob(F-statistic) } & & 39,17429 \\ \text { Sum squared resid } & & 2,364522 \\ \text { Durbin-Watson stat } & & 0,857753 \\ & & 19,78055 \\ \text { R-squared } & \text { Unweighted Statistics } & 2,003620 \\ \text { Sum squared resid } & & \\ \text { Durbin-Watson stat } & & \\ \text { (*) Signifikan pada taraf nyata 5 persen } & & \\ \text { (**) Signifikan pada taraf nyata 10 persen } & & \end{array}$

sebesar 1 persen akan mengurangi nilai ekspor produk HS 4001 (natural rubber) sebesar 1,233 persen. Koefisien yang bernilai negatif pada hasil estimasi telah sesuai dengan teori dan hipotesis dalam penelitian ini. Dengan kata lain, semakin jauh jarak ekonomi tentunya akan meningkatkan biaya, sehingga nilai ekspor akan menurun. Hal ini didukung oleh penelitian Mohmand YT et al. (2015) dan Suryana et al. (2014) menunjukkan bahwa jarak ekonomi berpengaruh negatif terhadap nilai ekspor. Krugman dalam Yuniarti (2007) menjelaskan bahwa jarak antar mitra dagang akan meningkatkan biaya transportasi meskipun jarak bukan satusatunya penentu biaya transportasi. Dengan adanya peningkatan biaya transportasi, maka ada biaya tambahan yang perlu dikeluarkan. Untuk menekan biaya tambahan tersebut maka volume ekspor produk harus dikurangi sehingga nilai ekspor yang semakin menurun akan berkurang.

Variabel harga ekspor memiliki pengaruh positif dan signifikan pada taraf nyata 5 persen. Apabila harga ekspor HS 4001 meningkat sebesar 1 persen maka nilai ekspor meningkat sebesar 1,371 persen (ceteris paribus). Hanoum (2016) menjelaskan bahwa peningkatan harga ekspor menggambarkan mutu dan kualitas suatu komoditas. Adanya peningkatan harga akan mendorong nilai ekspor komoditas agar dapat meningkat di pasar internasional. Dengan demikian nilai ekspor dan harga ekspor mempunyai korelasi positif.

Pada variabel nilai tukar riil, hasil estimasi menunjukkan koefisien negatif dan signifikan pada taraf nyata 10 persen. Apabila terjadi apresiasi nilai tukar riil sebesar 1 persen maka nilai ekspor akan menurun sebesar 0,601 persen. Penelitian Kanaya dan Firdaus (2014) menjelaskan bahwa saat nilai tukar negara pengekspor terdepresiasi, nilai ekspor dan volume ekspor negara tersebut akan meningkat. Sementara di negara importir, terjadi apresiasi nilai tukar yang menyebabkan harga produk mancanegara menjadi lebih mahal dibandingkan negara eksportir. Hal ini mendorong negara importir meningkatkan permintaan ekspor produk dari negara lain yang memiliki harga relatif lebih murah. Sementara variabel trade per GDP tidak berpengaruh terhadap nilai ekspor produk HS 4001 (natural rubber).

\section{KESIMPULAN DAN SARAN}

\section{KESIMPULAN}

Hasil penelitian menunjukkan bahwa berdasarkan nilai rata-rata RCA, produk HS 4001 (natural rubber) memiliki dayasaing di atas rata-rata dunia. Apabila dilihat dari 
market position, kinerja produk sudah cukup baik. Hasil EPD memperlihatkan bahwa produk berada pada posisi rising star di tiga negara, yaitu Brasil, Meksiko, dan Peru. Sementara Chile dan Argentina menempati posisi falling star dan Kolombia menempati posisi retreat. Dengan kata lain, Amerika Latin dapat dijadikan pasar potensial baru untuk produk natural rubber (HS 4001) Indonesia. Variabel yang memiliki pengaruh nyata positif terhadap nilai ekspor produk HS 4001 (natural rubber) ke enam negara Amerika Latin adalah PDB negara tujuan ekspor dan harga ekspor, sedangkan nilai tukar riil berpengaruh nyata negatif terhadap nilai ekspor produk HS 4001.

\section{SARAN}

1. Mutu produk yang berada pada posisi rising star perlu dipertahankan dan ditingkatkan agar produk ekspor tidak mengalami kemunduran kualitas yang dapat memengaruhi permintaan dan nilai ekspor Indonesia

2. Pemerintah perlu menjaga kestabilan nilai tukar karena variabel tersebut berpengaruh terhadap nilai ekspor produk HS 4001 (natural rubber) Indonesia ke Amerika Latin

\section{DAFTAR PUSTAKA}

[BPS] Badan Pusat Statistik [Internet]. http://bps.go.id [diakses pada 2017 Jun 9]

[Bappenas] Badan Perencanaan Pembangunan Nasional. 2009. Perdagangan dan Investasi di Indonesia: Sebuah Catatan tentang Dayasaing dan Tantangan ke Depan

Estherhuizen D. 2006. Measuring and analyzing competitiveness in the agribusiness sector: Methodological and analytical framework. University of Pretoria.

Hanoum FN. 2016. Analisis Kinerja Ekspor Elektronika Indonesia ke Amerika Latin
[Skripsi]. Bogor (ID): Institut Pertanian Bogor.

Hatab AA, Romstad E, Huo X. 2010. Determinants of Egyptian Agricultural Exports: A Gravity Model Approach. [Jurnal] Modern Economy Vol (1): 134143 [diunduh 2017 Mar 3]. Tersedia pada: http://www.SciRP.org/journal/me

Lipsey R, Courant P, Purvis D, Steiner P. 1997. Pengantar Makroekonomi, Jilid 1, Edisi 10. Maulana A, penerjemah. Jakarta (ID): Binarupa Aksara.

Kanaya IA, Firdaus M. 2014. Dayasaing dan Permintaan Ekspor Produk Biofarmaka Indonesia di Negara Tujuan Utama Periode 2003-2012. [Jurnal] Jurnal Manajemen \& Agribisnis Vol 11 (3): 183198; [diunduh 2017 Jun 30] Tersedia pada:

[Kemendag] Kementerian Perdagangan. [Internet]. [Diunduh 2017 Jun 7]. Tersedia pada:

http://www.kemendag.go.id/id/econo mic-profile/10-main-and-potentialcommodities

[Kemendag] Kementerian Perdagangan. [Internet]. [Diunduh 2017 Jun 7]. Tersedia pada:

http://djpen.kemendag.go.id/app_fron tend/contents/147-definisi-manfaat

Mohmand YT, Salman A, Mughal KS, Imran M, Nedim M. 2015. Export Potentials of Pakistan: Evidence from the Gravity Model of Trade. [Jurnal] European Journal of Economic Studies, 2015, Vol 14: 212-220. Tersedia pada: http:/ / ejournal2.com/journals_n/14509 67336.pdf

Razzaghi S, Ali M. Azad M. Sofi Y. 2012. The Determinants of Trade Flows between D8 Group Members through Gravity Model. [Jurnal] Journal Basic and Applied Scientific Research. Vol 2 (6): 5726-2731; [diunduh 2017 Mar 1] Tersedia pada: http:/ / textroad.com/pdf/JBASR/J.\%20 Basic.\%20Appl.\%20Sci.\%20Res.,\%202(6) 5726-5731,\%202012.pdf 
Suryana AT, Fariyanti A, Rifin A. 2014.Analisis Perdagangan Kakao Indonesia di Pasar Internasional. [Jurnal] Jurnal Tanaman Industri dan Penyegar, Vol 1 (1): 29-40. Tersedia pada: http://ejurnal.litbang.pertanian.go.id/i ndex.php/bultri/article/view/2321/201 4

Trade Map. 2017. Trade statistics for international business development. http://www.trademap.org/Index.aspx [diakses Januari 2017]

Yuniarti D. 2007.Analisis Determinan Perdagangan Bilateral Indonesia Pendekatan Gravity Model. [Jurnal] Jurnal Ekonomi Pembangunan Hal: 99109; [diunduh 2017 Jun 7] Tersedia pada: journal.uii.ac.id/index.php/JEP/article /download/509/421

[WB] Worldbank. 2017. World Development Indicator, The World Bank. http://databank.worldbank.org/data/r eports.aspx? source=world-

development-indicators [diakses Januari 2017] 


\section{Lampiran 1. Hasil Uji Chow Produk HS 4001 (Natural Rubber)}

Redundant Fixed Effects Tests

Equation: SUR

Test cross-section fixed effects

$\begin{array}{lccr}\text { Effects Test } & \text { Statistic } & \text { d.f. } & \text { Prob. } \\ \text { Cross-section F } & 23.361228 & (5,31) & 0.0000\end{array}$

\section{Lampiran 2. Hasil Uji Hausman Produk HS 4001 (Natural Rubber)}

Correlated Random Effects - Hausman Test

Equation: Untitled

Test cross-section random effects

$\begin{array}{lrrr}\text { Test Summary } & \text { Chi-Sq. Statistic } & \text { Chi-Sq. d.f. } & \text { Prob. } \\ \text { Cross-section random } & 15.093223 & 5 & 0.0100\end{array}$

Lampiran 3. Korelasi antar Variabel Independen Produk HS 4001 (Natural Rubber)

\begin{tabular}{|c|c|c|c|c|r|}
\hline & LN_GDPJ & LN_EP & LN_ECODIST & TRADE_GDP & LN_RER \\
\hline LN_GDPJ & 1.000000 & -0.045557 & 0.239893 & -0.355483 & -0.396391 \\
LN_EP & -0.045557 & 1.000000 & 0.068675 & 0.112190 & 0.052923 \\
LN_ECODIST & 0.239893 & 0.068675 & 1.000000 & 0.625373 & 0.321632 \\
TRADE_GDP & -0.355483 & 0.112190 & 0.625373 & 1.000000 & 0.357199 \\
LN_RER & -0.396391 & 0.052923 & 0.321632 & 0.357199 & 1.000000
\end{tabular}

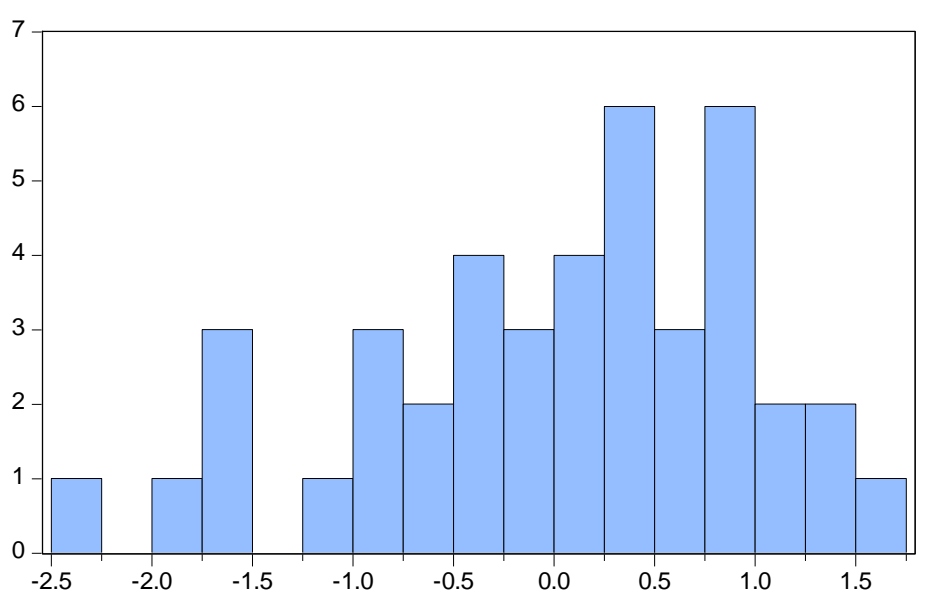

Series: Standardized Residuals Sample 20092015

Observations 42

Mean $\quad 2.78 \mathrm{e}-15$

Median $\quad 0.147568$

Maximum $\quad 1.655869$

Minimum $\quad-2.409041$

Std. Dev. $\quad 0.977482$

Skewness $\quad-0.566445$

Kurtosis $\quad 2.709577$

Jarque-Bera 2.393621

Probability $\quad 0.302156$ 
